\title{
Elevated tph2 mRNA Expression in a Rat Model of Chronic Anxiety
}

Nina C. Donner, Dipl.-Biol., M.S. ${ }^{1,{ }^{*}}$, Philip L. Johnson, Ph.D. ${ }^{2}$, Stephanie D. Fitz ${ }^{2}$, Karen E. Kellen ${ }^{1}$, Anantha Shekhar, M.D., Ph.D. ${ }^{2}$, and Christopher A. Lowry, Ph.D. ${ }^{1}$

${ }^{1}$ Department of Integrative Physiology and Center for Neuroscience, University of Colorado Boulder, Boulder, Colorado

${ }^{2}$ Department of Psychiatry, Institute of Psychiatric Research, Indiana University School of Medicine, Indianapolis, Indiana

\section{Abstract}

Background-Allelic variations in TPH2, the gene encoding tryptophan hydroxylase 2, the ratelimiting enzyme for brain serotonin (5-HT) biosynthesis, may be genetic predictors of panic disorder and panic responses to panicogenic challenges in healthy volunteers. To test the hypothesis that tph $2 \mathrm{mRNA}$ is altered in chronic anxiety states, we measured tph 2 expression in an established rat model of panic disorder.

Methods-We implanted 16 adult, male rats with bilateral guide cannulae and then primed them with daily injections of the corticotropin-releasing factor (CRF) receptor agonist, urocortin 1 (UCN1, 6 fmoles/100 $\mathrm{nl}$ per side, $\mathrm{n}=8)$ or vehicle $(\mathrm{n}=8)$ into the basolateral amygdaloid complex (BL) for 5 consecutive days. Anxiety-like behavior was assessed, $24 \mathrm{hr}$ prior to and $48 \mathrm{hr}$ following priming, in the social interaction (SI) test. A third group $(n=7)$ served as undisturbed home cage controls. All rats were killed 3 days after the last intra-BL injection to analyze tph 2 and slc6a4 (gene encoding the serotonin transporter, SERT) mRNA expression in the dorsal raphe nucleus (DR), the main source of serotonergic projections to anxiety-related brain regions, using in situ hybridization histochemistry.

Results-UCN1 priming increased anxiety-related behavior in the SI test compared to vehicleinjected controls and elevated tph2, but not slc6a4, mRNA expression in DR subregions, including the ventrolateral DR/ventrolateral periaqueductal gray (DRVL/VLPAG), a subregion previously implicated in control of panic-related physiologic responses. Tph2 mRNA expression in the DRVL/VLPAG was correlated with increased anxiety-related behavior.

Conclusion-Our data support the hypothesis that chronic anxiety states are associated with dysregulated tph2 expression.

(C) 2012 Wiley Periodicals, Inc.

"Correspondence to: Nina C. Donner, Department of Integrative Physiology and Center for Neuroscience, University of Colorado Boulder, 1725 Pleasant St, 114 Clare Small, Boulder, CO 80309-0354, nina.donner@ colorado.edu.

None of the authors report conflicts of interest related to the submitted manuscript. 


\section{Keywords}

anxiety/anxiety disorders; biological markers; mood disorders; panic attacks/agoraphobia; stress

\section{Introduction}

Anxiety disorders, including social anxiety disorder ${ }^{[1]}$ and panic disorder, ${ }^{[2]}$ are common emotional disorders, significantly impair overall quality of life, and affect about $19 \%$ of the male, and $30 \%$ of the female population at some point during life. ${ }^{[3-5]}$ The neural mechanisms underlying the manifestation of anxiety disorders are complex. However, two interconnected neural systems commonly dysregulated in patients with anxiety disorders are the extended amygdala ${ }^{[6,7]}$ and midbrain serotonergic systems. ${ }^{[8,9]}$

Stressful life events are likely a major determinant of vulnerability to affective and anxiety disorders. ${ }^{[10-12]}$ Corticotropin-releasing factor (CRF) and CRF-related neuropeptides acting at $\mathrm{CRF}$ type $1\left(\mathrm{CRF}_{1}\right)$ receptors are thought to play an important role in mediating the effects of perceived stress on anxiety-related systems. ${ }^{[13-15]}$ Systemic injections of $\mathrm{CRF}_{1}$ receptor antagonists are anxiolytic following acute intra-basolateral amygdaloid complex (BL) injections of the $\mathrm{CRF}_{1} / \mathrm{CRF}_{2}$ receptor agonist ${ }^{[16]}$ urocortin 1 (UCN1) and following repeated restraint, suggesting that $\mathrm{CRF}_{1}$ receptors mediate UCN1- and stress-induced increases in anxiety-related behavior. ${ }^{[17]}$ When injected into the BL, a key region controlling anxiety states, ${ }^{[18,19]} \mathrm{UCN} 1$ increases anxiety-related behavior in rats. ${ }^{[20]}$ Under chronic stress conditions, CRF receptor-mediated plasticity within the BL contributes to the development of chronic anxiety states. ${ }^{[21-24]}$ Repeated activation (priming) of CRF receptors within the BL with low-dose UCN1 results in a robust anxiety-like state that persists for more than 30 days in rats, ${ }^{[25]}$ as confirmed by reduced social interaction (SI) time in the SI test and panic-like physiologic responses, including tachycardia and increased respiratory rate, after intravenous administration of sodium lactate, ${ }^{[20,25]}$ an agent used as a research probe for panic disorder in human studies. ${ }^{[26-28]}$ In contrast, a single injection of the same "sub-threshold" UCN1 dose is insufficient to alter the animals' emotional state, ${ }^{[25]}$ indicating the need for BL-neuronal plasticity before a behavioral phenotype is evident.

Family and twin studies have consistently found that genetic factors explain approximately $48 \%$ of the variance in panic disorder, ${ }^{[29]}$ and serotonergic genes are important candidate genes for vulnerability to panic disorder. ${ }^{[30]}$ Tryptophan hydroxylase 2 (TPH2) is the ratelimiting enzyme for brain serotonin (5-HT) synthesis. ${ }^{[31]} \mathrm{TPH} 2$ allelic variants appear to be genetic predictors of panic disorder itself, ${ }^{[32,33]}$ susceptibility to panic attacks, ${ }^{[34]}$ and comorbidity between panic disorder and mood disorders ${ }^{[35]}$ (but see ${ }^{[36,37]}$ ). These studies are consistent with the hypothesis that allelic variation in $\mathrm{TPH} 2$ is associated with increased vulnerability to panic disorder.

Selective serotonin reuptake inhibitors (SSRIs) are common, effective treatments for panic disorder ${ }^{[38]}$ that target the serotonin transporter (SERT). A number of studies have found no association between a functional promoter polymorphism (serotonin transporter-linked polymorphic region (5-HTTLPR)) of SLC6A4 (the gene encoding SERT) and panic disorder. ${ }^{[39-44]}$ However, recent studies suggest that allelic variation in the SLC6A4 $3^{\prime}$ 
untranslated region may be associated with panic disorder ${ }^{[45,46]}$ whereas, allelic variation in the 5-HTTLPR may be associated with susceptibility to panic attacks in healthy volunteers. ${ }^{[47]}$

Given the functional interactions between the BL and the serotonergic dorsal raphe nucleus (DR), ${ }^{[48]}$ evidence for elevated brain serotonin turnover in panic disorder patients ${ }^{[49]}$ and for dysfunctional serotonergic systems in a rat model of panic disorder, ${ }^{[50]}$ we here test the hypothesis that $t p h 2$ and slc $6 a 4$ expression are dysregulated in a rat model of chronic anxiety with vulnerability to panic-like responses to sodium lactate. ${ }^{[20,25]}$ To test this hypothesis, we conducted sham- or UCN1 priming in the amygdala to generate a chronic anxiety state, and measured tph2 and slc6a4 mRNA expression within the DR using in situ hybridization histochemistry (ISHH).

\section{Materials and Methods}

\section{Animals}

Adult male Wistar rats (250-300 $\mathrm{g}$ in weight) from Harlan Laboratories (Indianapolis, IN) were habituated to the new facility for one week, and housed singly under a 12:12 hr light cycle (lights on at $07: 00 \mathrm{~h}$ ) at $22^{\circ} \mathrm{C}$ with ad libitum access to food and water. Sixteen rats were used for intra-BL priming, 16 age-matched conspecifics were used as partner rats in the SI test, and seven rats were kept undisturbed as home cage controls. All animal procedures were conducted at Indiana University Purdue University at Indianapolis School of Medicine (Indianapolis, IN) following IACUC committee approval, and were consistent with the Guide for the Care and Use of Laboratory Animals. ${ }^{[51]}$ All efforts were made to minimize animal numbers and suffering.

\section{Experimental Design}

We utilized an established rat model of chronic anxiety, characterized by increased anxiety in the SI test and panic-like physiologic responses following intravenous infusions of sodium lactate. ${ }^{[20,25]}$ The experimental timeline is illustrated in Figure 1. Under deep isoflurane anesthesia (MGX Research Machine; Vetamic, Rossville, IN), 16 rats were implanted with one stainless steel guide cannula per brain hemisphere (26 ga, Cat. No. C315GS-4, Plastics One, Roanoke, VA) above the BL at the following coordinates, ${ }^{[20]}$ anterior/posterior: $-2.1 \mathrm{~mm}$ bregma; lateral from midline (bilateral): $\pm 5.0 \mathrm{~mm}$ bregma; depth from skull surface: $-8.5 \mathrm{~mm}$ bregma (Fig. 2), ${ }^{[52]}$ incisor bar at $-3.3 \mathrm{~mm}$. After surgery, guide cannulae were sealed with dummy cannulae (Plastics One), and rats were allowed to recover. Six days later, experimental rats were habituated to the SI arena, and tested in the SI test on the following day (Day 0) to measure their baseline anxiety-related behavior. ${ }^{[53]}$ Starting one day afterwards, rats received daily, bilateral intra-BL injections of vehicle (1\% bovine serum albumin, Cat. No. A2153, Sigma-Aldrich, St. Louis, MO, in sterile $0.9 \%$ saline, $n=8$ ) or the CRF receptor agonist UCN1 (Cat. No. U6631, SigmaAldrich; 6 fmoles UCN1/100 nl vehicle per side, $n=8$ ) into the BL at 09:00 h for 5 consecutive days. ${ }^{[20]}$ This intra-BL priming paradigm produces long-lasting anxiety-like behavior in the SI test and panic-like physiologic responses following lactate challenge, whereas a single bilateral injection of the same "sub-threshold" dose of UCN1 is not 
sufficient to exert anxiogenic actions. ${ }^{[20,25]}$ This increased anxiety-like state with vulnerability to panic-like responses is thought to be dependent on N-methyl-D-aspartic acid (NMDA) receptor-dependent neuronal plasticity in the BL. ${ }^{[25]}$ Two days after the last injection, the rats were tested in the SI test again to confirm the development of a chronic anxiety-like state. We did not challenge rats with sodium lactate in this study as our previous studies have shown that sodium lactate, ${ }^{[50]}$ but not exposure to the SI test, ${ }^{[48]}$ profoundly activates DR serotonergic neurons, and therefore may, by itself, influence serotonergic gene expression. Home cage control rats remained undisturbed during the duration of the experiment $(n=7)$. One day after the postpriming SI test, all rats were killed between 09:00 and 10:00 $\mathrm{h}$ via rapid decapitation. Their brains were collected, shipped overnight on dry ice to the University of Colorado Boulder (Boulder, CO), and stored there at $-80^{\circ} \mathrm{C}$ until analysis of $t p h 2$ and slc $6 a 4$ expression. We intentionally killed all rats $24 \mathrm{hr}$ after the postpriming SI test, and not earlier, because certain behavioral tests using socially interactive paradigms themselves, such as social defeat, have been shown to increase rat tph 2 mRNA expression within $4 \mathrm{hr}$ post-exposure. ${ }^{[54]}$

\section{SI Test}

The SI test was conducted as described previously. ${ }^{[18,19,55,56]}$ Each experimental rat was exposed to an unfamiliar, age- and weight-matched, male partner rat for $5 \mathrm{~min}$ in a $91.5 \mathrm{~cm}$ $\times 91.5 \mathrm{~cm}$ solid wooden box with 30.5-cm high walls and an open top, under low-light conditions between 09:00 and 13:00 h. A video camera above the arena recorded the behavior for later analysis with "The Observer" (version 5.0, Noldus Information Technologies, Wageningen, The Netherlands). SI time was defined as any behavior initiated or fully participatory by the experimental rat: face-on contact, sniffing, following, grooming, crawling over or under the partner. No experimental rat was exposed to the same partner rat more than once. Decreased SI time is indicative of an anxiogenic treatment effect. ${ }^{[53]}$

\section{Brain Tissue Sectioning and Verification of Cannulae Placements}

Forebrains were cryosectioned coronally at $30 \mu \mathrm{m}$ between approximately -1.40 and -3.60 mm bregma, ${ }^{[51]}$ thaw-mounted onto Vista-Vision HistoBond microscope slides (VWR Scientific, West Chester, PA), stained with cresyl violet, ${ }^{[52]}$ and cover-slipped with Entellan mounting medium (Cat. No. 14802, EMS, Hatfield, PA). Cannulae placements (Fig. 2) were identified with reference to a stereotaxic rat brain atlas. ${ }^{[52]}$ Only rats with both injection sites within the BL region or just ventral of the BL (in which case UCN1 is expected to reach the BL along the cannula tract) were used for analysis of behavior and gene expression (Fig. 3). No outliers were identified. Hindbrains were cryosectioned at $12 \mu \mathrm{m}$ between approximately -7.58 and $-8.67 \mathrm{~mm}$ bregma, and sections were thaw-mounted onto VistaVision HistoBond microscope slides (VWR Scientific).

\section{tph2 and slc6a4 in situ Hybridization Histochemistry (ISHH)}

A 583-base pair fragment of tph2 cDNA was transcribed and radiolabeled with [35-S]uridine-5'-triphosphate (UTP, Cat. No. 5610301, MP Biomedicals, Santa Ana, CA) using T7 RNA-polymerase (Promega, Madison, WI) to create a cRNA probe complementary to bases 761-1343 of rat $t p h 2$ mRNA. The probe was cleaned (RNeasy kit, Cat. No. 74104, Qiagen, 
Valencia, CA), and used in an ISHH assay as described previously. ${ }^{[57]}$ To detect slc6a4 mRNA, a synthetic 50-base antisense oligonucleotide probe (5'-ACT GCA GAG TAC CCA TTG GAT ATT TGG CTA GGC TCT GCC CTG TCC GCT GT-3', Integrated DNA Technologies, Coralville, IA) complementary to bases 207-256 of rat slc6a4 mRNA was used. The probe was labeled at the $3^{\prime}$ end with [35-S]-deoxyadenosine-5'-triphosphate (dATP, Cat. No. 5620001, MP Biomedicals, Santa Ana, CA) using terminal deoxynucleotidyl transferase (TdT, 20 U/ $\mu$ l, Cat. No. EP0161, Fermentas, Glen Burnie, MD) for $1 \mathrm{hr}$ at $37^{\circ} \mathrm{C}$ in a water bath, cleaned using a QIAquick nucleotide removal kit (Cat. No. 28304, Qiagen, Valencia, CA), and used in an ISHH assay as described previously. ${ }^{[58]}$ Airdried slides were apposed to a BioMax MR autoradiography film (Cat. No. 871 5187, Carestream Health, Rochester, NY) for 7 (tph2) or 11 (slc6a4) days, respectively.

\section{Semiquantitative Analysis of Gene Expression}

Digital autoradiography images were analyzed with ImageJ (NIH, Bethesda, MD) while blinded to the treatment groups to measure gray value $\times$ area (equivalent to $t p h 2$ or slc6a4 mRNA expression) using matrices in the shape of each subdivision of the brainstem DR. Area $\left(\mathrm{mm}^{2}\right)$ was defined as the area (within each matrix) that fell above a gray value threshold that was kept consistent throughout each gene's analysis. Based on Gardner et al. ${ }^{[54]}$ and Abrams et al., ${ }^{[59]}$ a total of 14 rostro-caudal sections, designated levels +7 to -6 (Fig. 4), containing seven major subdivisions of the DR were analyzed (rostral aspect of the dorsal raphe nucleus, dorsal part, rDRD, -7.580 to $-7.916 \mathrm{~mm}$ bregma; rostral aspect of the dorsal raphe nucleus, ventral part, rDRV, -7.580 to $-7.916 \mathrm{~mm}$ bregma; caudal aspect of the dorsal raphe nucleus, dorsal part, cDRD, -8.000 to $-8.336 \mathrm{~mm}$ bregma; caudal aspect of the dorsal raphe nucleus, ventral part, cDRV, -8.000 to $-8.504 \mathrm{~mm}$ bregma; dorsal raphe nucleus, ventrolateral part/ventrolateral periaqueductal gray region, DRVL/VLPAG, -7.832 to $-8.504 \mathrm{~mm}$ bregma; dorsal raphe nucleus, caudal part, DRC, -8.420 to $-8.672 \mathrm{~mm}$ bregma; dorsal raphe nucleus, interfascicular part, DRI, -8.420 to $-8.672 \mathrm{~mm}$ bregma $^{[52]}$ ). An average value was computed for the DRVL/VLPAG using values from both the left and right hemisphere. The background of each image, measured in the surrounding midbrain tegmentum, was subtracted from each value. Throughout the 14 rostrocaudal levels, values for each of the seven DR subdivisions were averaged, and average tph2 and slc6a4 expression levels in the entire DR were also calculated for each rat.

\section{Statistical Analysis}

Data were analyzed using PASW (version 19.0, SPSS Inc., Chicago, IL) after elimination of statistical outliers. ${ }^{[60]}$ SI time was analyzed using a repeated-measures analysis of variance (ANOVA) with treatment (vehicle or UCN1) as the between-subjects factor, and time (baseline versus postpriming SI test) as the within-subjects factor, and Fisher's protected least significant difference (LSD) tests where appropriate. To determine if vehicle priming altered either tph2 or slc6a4 mRNA expression, relative to home cage controls, and if UCN1 priming altered tph 2 or slc $6 a 4$ mRNA expression, relative to vehicle-primed rats, we conducted two separate repeated-measures ANOVAs, using treatment as the betweensubjects factor and DR subdivision as the within-subjects factor. Where appropriate, Fisher's protected LSD tests were applied for each of the seven subdivisions of the DR to reveal subdivision-specific treatment effects on gene expression. To compare treatment effects on 
the average tph2 and slc6a4 mRNA expression in the entire DR, two separate Student's $t$ tests were used to compare vehicle-primed rats with home cage controls, and UCN1-primed rats with vehicle-primed controls. Significance was accepted at $P<.05$. Values are shown as the mean + the standard error of the mean (SEM).

\section{Results}

\section{Behavior in the SI Test}

There was no difference in SI time between vehicle and UCN1 groups on Day 0, prior to priming, but $48 \mathrm{hr}$ after the final intra-BL priming injection, the UCN1-treated rats displayed increased anxiety-like behavior in the SI test, relative to vehicle-treated controls (Fig. 5; treatment, $F_{(1,14)}=3.73, P=0.07$; time, $F_{(1,14)}=3.65, P=0.08$; time $\times$ treatment, $F_{(1,14)}=$ $12.11, P<0.01)$. Also, UCN1-primed rats had significantly less SI time on Day 7 compared to the initial test on Day $0(t=4.02, P<0.01)$, whereas vehicle-primed control rats displayed no difference in SI time compared to Day 0.

\section{tph2 mRNA Expression}

There were no differences between $t p h 2$ expression in vehicle-primed rats and home cage control rats (treatment, $F_{(1,13)}=1.28, P=0.28$; subdivisions, $F_{(6,8)}=21.48, P<.001$; subdivisions $\times$ treatment, $\left.F_{(6,8)}=0.36, P=0.90\right)$. UCN1 priming had a significant treatment effect on $t p h 2$ mRNA expression compared to vehicle-treated rats $\left(\right.$ treatment, $F_{(1,14)}=$ 41.77, $P<0.05$; subdivisions, $F_{(6,9)}=32.02, P<.001$; subdivisions $\times$ treatment, $F_{(6,9)}=$ $2.42, P<0.05$, Fig. 6). Fisher's protected LSD post hoc analyses of each of the seven DR subdivisions revealed significantly elevated tph 2 mRNA expression within the caudal DRV (cDRV, $P<0.05$, Fig. 6D) and within the DRVL/VLPAG of UCN1-treated rats compared to the vehicle group $(P<0.01$, Fig. $6 \mathrm{E})$. No other subdivision showed significant differences in priming-induced tph 2 expression relative to the vehicle-primed rats. tph 2 mRNA expression in the entire DR (average of all subregions) did not differ significantly between treatment groups $\left(F_{(2,20)}=2.98, P=.074\right.$; data not shown $)$.

\section{slc6a4 mRNA Expression}

No differences in slc6a4 mRNA expression were detected between the vehicle-primed group and home cage controls (treatment, $F_{(1,13)}=0.01, P=0.94$; subdivisions, $F_{(6,8)}=26.61, P$ $<0.001$; subdivisions $\times$ treatment, $F_{(6,8)}=0.34, P=0.91$; Fig. 7). Compared to vehicleprimed rats, UCN1 priming did not alter the expression of slc6a4 mRNA in subdivisions of the DR (treatment, $F_{(1,14)}=0.05, P=0.82$; subdivisions, $F_{(6,9)}=37.98, P<0.001$; subdivisions $\times$ treatment, $F_{(6,9)}=2.42, P=0.90$; Fig. 7). Slc6a4 mRNA expression in the entire DR (average of all subregions) did not differ between treatment groups $\left(F_{(2,20)}=\right.$ $0.02, P=0.98$; data not shown).

\section{Correlation of Behavior and Gene Expression}

To address the question of whether the UCN1-induced change in tph2 mRNA expression, which presumably already existed during the time of the second behavioral SI test one day prior to the collection of the brains, was linked to the observed chronic anxiety state, correlation analyses of tph2 mRNA expression in the DRVL/VLPAG or cDRV and SI 
behavior in the SI test of Day 7 were performed for both the vehicle- and the UCN1-primed rats (Fig. 8). Anxiety-like behavior during the second SI test was strongly correlated with tph2 mRNA expression in the DRVL/VLPAG region $\left(r=0.73, r^{2}=0.53, P<0.01\right)$ but not the cDRV region $\left(r=0.46, r^{2}=0.21, P=0.07\right)$. Anxiety-like behavior during the second SI test was not correlated with slc6a4 mRNA expression in either the DRVL/VLPAG or cDRV.

\section{Discussion}

Intra-BL priming with UCN1, a previously characterized rat model of chronic anxiety with vulnerability to panic-like physiological responses to sodium lactate challenge (increases in blood pressure, heart rate, and respiratory rate), ${ }^{[20,25]}$ produced a robust anxiety-like state as measured in the SI test. In the same rats, $t p h 2$ expression was significantly elevated $24 \mathrm{~h}$ following the SI test in both the cDRV and in the DRVL/VLPAG region. However, only tph2 expression in the DRVL/VLPAG showed a strong, positive correlation with increased anxiety-like behavior in the post-priming SI test. No other DR subdivision revealed altered tph2 expression.

Our finding that the priming-induced anxiety-like state is associated with increased tph2 mRNA expression in the DRVL/VLPAG is consistent with other models of chronic anxiety states that also demonstrated site-specific increases in tph 2 mRNA expression in the DRVL/ VLPAG. For example, adverse early-life experiences, such as maternal separation of neonatal rats, lead to a chronic anxiety-like state, ${ }^{[61]}$ enhanced vulnerability to social defeat induced increases in tph2 mRNA expression specifically within the DRVL/VLPAG region during adulthood. ${ }^{[54]}$ Likewise, neonatal administration of Salmonella endotoxin (containing gram-negative lipopolysaccharide, LPS) to rat pups, which results in an increased anxiety state that lasts into adulthood, ${ }^{[62,63]}$ also elevates $t p h 2$ mRNA expression in the DRVL/ VLPAG, but not in other DR subdivision. ${ }^{[64]}$ The similarities among these three individual rat models indicate that site-specific increases in tph2 mRNA expression in the DRVL/ VLPAG region may be a common feature of the development or maintenance of stressinduced chronic anxiety states.

Although we were not able test both SI behavior and panic-like physiological responses in the present study, panic-like physiological responses have been detected when rats of the same intra-BL UCN1-priming paradigm were infused intravenously with sodium lactate ${ }^{[20,25]}$, an agent that is also used to probe for panic disorder in human studies. ${ }^{[27,28,65,66]}$ This vulnerability to panic-like responses following amygdala priming may be related to our finding that increased anxiety-like behavior was strongly correlated with elevated $t p h 2$ expression in the DRVL/VLPAG, because several other lines of evidence suggest that DRVL/VLPAG serotonergic neurons play a role in control of panic-like responses. For example, an acute challenge with panicogenic stimuli such as sodium lactate or hypercapnia, or exposure to adverse stimuli such as forced swimming in cold water, ${ }^{[67,68]}$ strongly activates serotonergic neurons in the DRVL/VLPAG region, as indicated by increases in c-Fos expression. ${ }^{[50,69-71]}$ In studies using a different rat model of panic disorder, ${ }^{[26,65,66]}$ we have shown that sodium lactate increases c-Fos expression in DRVL/VLPAG serotonergic neurons of control rats, but not in rats made panic-prone by 
disinhibition of the medial hypothalamus. ${ }^{[50,72]}$ These data suggest that the DRVL/VLPAG serotonergic neurons may in fact inhibit panic-like responses. The consequences of priminginduced increases in tph2 mRNA expression in the DRVL/VLPAG for serotonergic neurotransmission are uncertain. Increased $t p h 2$ expression in the DRVL/VLPAG may result in increased TPH2 protein, increased 5-HT synthesis, and increased 5-HT release in the DRVL/VLPAG and targets of DRVL/VLPAG serotonergic neurons. Alternatively, a selective increase in serotonergic neurotransmission in the DRVL/VLPAG itself could preferentially activate autoinhibitory $5-\mathrm{HT}_{1 \mathrm{~A}}$ receptors, resulting in overall decreased serotonergic output from the DRVL/VLPAG to distal target sites. Finally, increased $t p h 2$ mRNA expression could be a compensatory response to decreased serotonergic neural activity.

The DRVL/VLPAG contains large, multipolar 5-HT neurons ${ }^{[73]}$ that form part of a sympatho-motor command center, controlling both sympathetic outflow via neuronal signaling to the adrenal medulla and motor activity via innervation of hind limb muscles. ${ }^{\text {[74] }}$ Consistent with these anatomic findings, the DRVL/VLPAG is thought to promote passive stress coping. ${ }^{[75,76]}$ Stimulation of the VLPAG region results in passive emotional coping, including behavioral quiescence, hyporeactivity to environmental stimuli, hypotension, and bradycardia. ${ }^{[75,76]}$ Therefore, dysfunction of this region could result in dysfunctional emotional coping strategies. One target region of the DRVL/VLPAG is the dorsal periaqueductal gray (DPAG), an area known to facilitate a panic/escape-like fight-or-flight response if disinhibited. ${ }^{[77]}$ Activation of $5-\mathrm{HT}_{1 \mathrm{~A}}$ receptors in the DPAG inhibits panic/ escape-like fight-or-flight responses, and therefore dysregulation of serotonergic signaling in this region may lead to increased vulnerability to panic-like responses. The DRVL/VLPAG serotonergic neurons also project to the rostral ventrolateral medulla ( $\mathrm{RVLM}^{[78]}$ ); stimulation of the DRVL/VLPAG region induces hypotension and sympathoinhibition, which can be prevented by activation of $5-\mathrm{HT}_{1 \mathrm{~A}}$ receptors in the RVLM. ${ }^{[79,80]}$ The DRVL also projects to the perifornical region $(\mathrm{PeF})$ of the lateral hypothalamus, ${ }^{[81,82]}$ a region that contains arousal-promoting orexin/hypocretin neurons implicated in anxiety disorders. ${ }^{[83]}$ Orexin/hypocretin neurons appear to be tonically inhibited by serotonergic input from the DR under normal conditions. ${ }^{[82,84]}$ Thus, serotonergic neurotransmission arising from the DRVL/VLPAG acting in the DPAG, RVLM, and the PeF of the lateral hypothalamus acts to inhibit panic-like behavioral and autonomic responses; dysregulation of this serotonergic system would be predicted to cause disinhibition of those target areas, leading to panic and/or anxiety-like responses, including tachycardia, hypertension, and a state of hypervigilance or hyperarousal (see Fig. 9 for a hypothetical mechanistic model).

Amygdala priming with UCN1 also increased tph 2 mRNA expression in the cDRV, and the correlation between tph 2 mRNA expression in the cDRV and anxiety-like behavior in the SI test approached statistical significance $(P=0.074)$. The cDRV contains large numbers of neurons projecting to anxiety-related forebrain structures, such as the BL. ${ }^{[85]}$ If the hypothesis that increased tph 2 mRNA expression ultimately leads to disinhibition of target areas holds true, this could mean that increased tph2 expression in the cDRV creates a positive feedback loop to the BL, increasing rather than inhibiting the effects of intra-BL priming. The DRV is also the main source of efferent projections to the sensorimotor 
cortex, ${ }^{[86]}$ and DR serotonergic neurons recently have been shown to encode specific sensorimotor events. ${ }^{[87]}$ Thus, increases in tph2 in the cDRV may influence encoding of specific sensorimotor events. This hypothesis is consistent with findings that panic disorder patients have altered processing of sensory information. ${ }^{[88]}$

The mechanisms underlying selective increases in tph2 mRNA expression in the DRVL/ VLPAG and cDRV region are not clear, but may involve activation of specific afferents. The BL does not give rise to direct projections to the DR. Most likely, UCN1 priming of the BL causes altered signaling to the central amygdaloid complex (CE), bed nucleus of the stria terminalis (BST), and/or the medial prefrontal cortex (mPFC), which are all known to innervate the DR, with strong input to the caudal DR and to the DRVL/VLPAG region, ${ }^{[89]}$ and may thus alter tph2 expression in the DRVL/VLPAG.

Our observation that expression of slc $6 a 4$ mRNA was not altered by intra-BL priming with UCN1 is consistent with several studies that failed to find associations between allelic variation in SLC6A4 and panic disorder. ${ }^{[39-44]}$ Although SERT binding potential is higher in a number of brain regions in male panic disorder patients, ${ }^{[90]}$ unfortunately, no studies have evaluated TPH2 or SLC6A4 mRNA expression in postmortem tissues from panic disorder patients. Our results are, however, inconsistent with a previous study investigating the effects of neonatal maternal separation on vulnerability to social stressors later in life. In this study, slc6a4 mRNA was increased, again, specifically in the DRVL/VLPAG region of rats that had been exposed to a combination of maternal separation as newborns and acute social defeat as adults. ${ }^{[58]}$ This may indicate that slc6a4 expression is more vulnerable to later-life social stressors if a vulnerability was created earlier in life, for example during a critical developmental window, but that slc6a4 expression is fairly resilient toward repeated stressors that have their first occurrence during adulthood.

\section{Conclusion}

Our study reveals a potential neuroanatomical pathway by which overstimulation of CRF receptors in the BL, for example during chronic stress exposure, ${ }^{[21]}$ could lead to dysregulation of serotonergic control of anxiety-related brain circuits. This neuronal pathway may contribute to the development of a chronic anxiety state, including vulnerability to panic. Our finding that a chronic anxiety state is associated with selective dysregulation of the DRVL/VLPAG subset of serotonergic neurons, a panic-related subset of serotonergic neurons that is highly sensitive to hypercapnia ${ }^{[70]}$ and sodium lactate, ${ }^{[50]}$ is consistent with Klein's suffocation false alarm theory of panic disorder. ${ }^{[91,92]}$ Finally, as suggested by Davies et al., ${ }^{[93]}$ dysregulation of DRVL/VLPAG serotonergic neurons may account for the association between hypertension and panic disorder. Further characterization of the DRVL/VLPAG group of serotonergic neurons may lead to novel therapeutic strategies for the treatment of anxiety disorders, including panic disorder.

\section{Acknowledgments}

This study was supported by a collaborative grant between Christopher A. Lowry at the University of Colorado Boulder and Anantha Shekhar at the Indiana University School of Medicine (NIH R01MH065702-08). 


\section{References}

1. Fink M, Akimova E, Spindelegger C, et al. Social anxiety disorder: epidemiology, biology and treatment. Psychiatr Danub. 2009; 21(4):533-542. [PubMed: 19935490]

2. Stein D. Panic disorder: the psychobiology of external treat and introceptive distress. CNS Spectr. 2008; 13(1):26-30. [PubMed: 18204411]

3. Greenberg P, Sisitsky T, Kessler R, et al. The economic burden of anxiety disorders in the 1990s. J Clin Psychiatry. 1999; 60(7):427-435. [PubMed: 10453795]

4. Karsnitz D, Ward S. Spectrum of anxiety disorders: diagnosis and pharmacologic treatment. J Midwifery Womens Health. 2011; 56(3):266-281. [PubMed: 21535374]

5. Hoffman DL, Dukes EM, Wittchen HU. Human and economic burden of generalized anxiety disorder. Depress Anxiety. 2008; 25(1):72-90. [PubMed: 17146763]

6. Shekhar A, Sajdyk TS, Keim SR, et al. Role of the basolateral amygdala in panic disorder. Ann NY Acad Sci. 1999; 877:747-750. [PubMed: 10415697]

7. Rauch SL, Shin LM, Wright CI. Neuroimaging studies of amygdala function in anxiety disorders. Ann NY Acad Sci. 2003; 985(1):389-410. [PubMed: 12724173]

8. Naughton M, Mulrooney JB, Leonard BE. A review of the role of serotonin receptors in psychiatric disorders. Hum Psychopharmacol. 2000; 15(6):397-415. [PubMed: 12404302]

9. Graeff FG, Guimaraes FS, De Andrade TG, Deakin JF. Role of 5-HT in stress, anxiety, and depression. Pharmacol Biochem Behav. 1996; 54(1):129-141. [PubMed: 8728550]

10. Caspi A, Sugden K, Moffitt TE, et al. Influence of life stress on depression: moderation by a polymorphism in the 5-HTT gene. Science. 2003; 301(5631):386-389. [PubMed: 12869766]

11. Kendler KS, Kuhn JW, Prescott CA. Childhood sexual abuse, stressful life events and risk for major depression in women. Psychol Med. 2004; 34(8):1475-1482. [PubMed: 15724878]

12. Hammen C. Association between recent stressful life events and prevalence of depression, anxiety and PTSD differs according to exposure to childhood adversity. Evid Based Ment Health. 2011; 14(1):9. [PubMed: 21266606]

13. Sandi C, Cordero MI, Ugolini A, et al. Chronic stress-induced alterations in amygdala responsiveness and behavior-modulation by trait anxiety and corticotropin-releasing factor systems. Eur J Neurosci. 2008; 28(9):1836-1848. [PubMed: 18973598]

14. Kozicz T, Bordewin LA, Czeh B, et al. Chronic psychosocial stress affects corticotropin-releasing factor in the paraventricular nucleus and central extended amygdala as well as urocortin 1 in the non-preganglionic Edinger-Westphal nucleus of the tree shrew. Psychoneuroendocrinology. 2008; 33(6):741-754. [PubMed: 18394812]

15. Gallagher JP, Orozco-Cabal LF, Liu J, Shinnick-Gallagher P. Synaptic physiology of central CRH system. Eur J Pharmacol. 2008; 583(2-3):215-225. [PubMed: 18342852]

16. Vaughan J, Donaldson C, Bittencourt J, et al. Urocortin, a mammalian neuropeptide related to fish urotensin I and to corticotropin-releasing factor. Nature. 1995; 378(6554):287-292. [PubMed: 7477349]

17. Gehlert DR, Shekhar A, Morin SM, et al. Stress and central urocortin increase anxiety-like behavior in the social interaction test via the CRF1 receptor. Eur J Pharmacol. 2005; 509(2-3): 145-153. [PubMed: 15733549]

18. Sanders SK, Shekhar A. Anxiolytic effects of chlordiazepoxide blocked by injection of GABAA and benzodiazepine receptor antagonists in the region of the anterior basolateral amygdala of rats. Biol Psychiatry. 1995; 37(7):473-476. [PubMed: 7786962]

19. Sanders SK, Shekhar A. Regulation of anxiety by GABAA receptors in the rat amygdala. Pharmacol Biochem Behav. 1995; 52(4):701-706. [PubMed: 8587908]

20. Sajdyk TJ, Schober DA, Gehlert DR, Shekhar A. Role of corticotropin-releasing factor and urocortin within the basolateral amygdala of rats in anxiety and panic responses. Behav Brain Res. 1999; 100(1-2):207-215. [PubMed: 10212068]

21. Shekhar A, Truitt W, Rainnie D, Sajdyk T. Role of stress, corticotrophin releasing factor (CRF) and amygdala plasticity in chronic anxiety. Stress. 2005; 8(4):209-219. [PubMed: 16423710] 
22. Bhatnagar S, Vining C, Denski K. Regulation of chronic stress-induced changes in hypothalamicpituitary-adrenal activity by the basolateral amygdala. Ann NY Acad Sci. 2004; 1032:315-319. [PubMed: 15677440]

23. Gilabert-Juan J, Castillo-Gomez E, Perez-Rando M, et al. Chronic stress induces changes in the structure of interneurons and in the expression of molecules related to neuronal structural plasticity and inhibitory neurotransmission in the amygdala of adult mice. Exp Neurol. 2011; 232(1):33-40. [PubMed: 21819983]

24. Qin M, Xia Z, Huang T, Smith CB. Effects of chronic immobilization stress on anxiety-like behavior and basolateral amygdala morphology in Fmrl knockout mice. Neuroscience. 2011; 194:282-290. [PubMed: 21723920]

25. Rainnie DG, Bergeron R, Sajdyk TJ, et al. Corticotrophin releasing factor-induced synaptic plasticity in the amygdala translates stress into emotional disorders. J Neurosci. 2004; 24(14): 3471-3479. [PubMed: 15071094]

26. Sajdyk TJ, Keim SR, Thielen SR, et al. Measurement of paniclike responses following intravenous infusion of sodium lactate in panic-prone rats. Curr Protoc Neurosci. 2003; 9(17):1-19.

27. Peskind ER, Jensen CF, Pascualy M, et al. Sodium lactate and hypertonic sodium chloride induce equivalent panic incidence, panic symptoms, and hypernatremia in panic disorder. Biol Psychiatry. 1998; 44(10):1007-1016. [PubMed: 9821565]

28. Rifkin A, Siris SG. Panic disorder: response to sodium lactate and treatment with antidepressants. Prog Neuropsychopharmacol Biol Psychiatry. 1985; 9(1):33-38. [PubMed: 3887490]

29. Hettema JM, Neale MC, Kendler KS. A review and meta-analysis of the genetic epidemiology of anxiety disorders. Am J Psychiatry. 2001; 158(10):1568-1578. [PubMed: 11578982]

30. Maron E, Shlik J. Serotonin function in panic disorder: important, but why? Neuropsychopharmacology. 2006; 31(1):1-11. [PubMed: 16132063]

31. Zhang X, Beaulieu J, Sotnikova T, et al. Tryptophan hydroxylase-2 controls brain serotonin synthesis. Science. 2004; 305(5681):217. [PubMed: 15247473]

32. Kim YK, Lee HJ, Yang JC, et al. A tryptophan hydroxylase 2 gene polymorphism is associated with panic disorder. Behav Genet. 2009; 39(2):170-175. [PubMed: 19132526]

33. Maron E, Toru I, Must A, et al. Association study of tryptophan hydroxylase 2 gene polymorphisms in panic disorder. Neurosci Lett. 2007; 411(3):180-184. [PubMed: 17123728]

34. Maron E, Toru I, Tasa G, et al. Association testing of panic disorder candidate genes using CCK-4 challenge in healthy volunteers. Neurosci Lett. 2008; 446(2-3):88-92. [PubMed: 18832011]

35. Campos SB, Miranda DM, Souza BR, et al. Association study of tryptophan hydroxylase 2 gene polymorphisms in bipolar disorder patients with panic disorder comorbidity. Psychiatr Genet. 2011; 21(2):106-111. [PubMed: 21085052]

36. Yoon HK, Yang JC, Lee HJ, Kim YK. The association between serotonin-related gene polymorphisms and panic disorder. J Anxiety Disord. 2008; 22(8):1529-1534. [PubMed: 18436425]

37. Mossner R, Freitag CM, Gutknecht L, et al. The novel brain-specific tryptophan hydroxylase-2 gene in panic disorder. J Psychopharmacol. 2006; 20(4):547-552. [PubMed: 16401665]

38. Bakker A, van Balkom AJ, van Dyck R. Selective serotonin reuptake inhibitors in the treatment of panic disorder and agoraphobia. Int Clin Psychopharmacol. 2000; 15(Suppl 2):S25-S30. [PubMed: 11110016]

39. Hamilton SP, Heiman GA, Haghighi F, et al. Lack of genetic linkage or association between a functional serotonin transporter polymorphism and panic disorder. Psychiatr Genet. 1999; 9(1):16. [PubMed: 10335545]

40. Olesen OF, Bennike B, Hansen ES, et al. The short/long polymorphism in the serotonin transporter gene promoter is not associated with panic disorder in a Scandinavian sample. Psychiatr Genet. 2005; 15(3):159. [PubMed: 16094247]

41. Deckert J, Catalano M, Heils A, et al. Functional promoter polymorphism of the human serotonin transporter: lack of association with panic disorder. Psychiatr Genet. 1997; 7(1):45-47. [PubMed: 9264139] 
42. Domschke K, Braun M, Ohrmann P, et al. Association of the functional -1019C/G 5-HT1A polymorphism with prefrontal cortex and amygdala activation measured with $3 \mathrm{~T}$ fMRI in panic disorder. Int J Neuropsychopharmacol. 2006; 9(3):349-355. [PubMed: 16316476]

43. Blaya C, Salum GA, Lima MS, et al. Lack of association between the serotonin transporter promoter polymorphism (5-HTTLPR) and panic disorder: a systematic review and meta-analysis. Behav Brain Funct. 2007; 3:41-51. [PubMed: 17705872]

44. Blaya C, Salum GA, Moorjani P, et al. Panic disorder and serotonergic genes (SLC6A4, HTR1A and $H T R 2 A)$ : association and interaction with childhood trauma and parenting. Neurosci Lett. 2010; 485(1):11-15. [PubMed: 20817074]

45. Strug LJ, Suresh R, Fyer AJ, et al. Panic disorder is associated with the serotonin transporter gene (SLC6A4) but not the promoter region (5-HTTLPR). Mol Psychiatry. 2010; 15(2):166-176. [PubMed: 18663369]

46. Gyawali S, Subaran R, Weissman MM, et al. Association of a polyadenylation polymorphism in the serotonin transporter and panic disorder. Biol Psychiatry. 2010; 67(4):331-338. [PubMed: 19969287]

47. Maron E, Tasa G, Toru I, et al. Association between serotonin-related genetic polymorphisms and CCK-4-induced panic attacks with or without 5-hydroxytryptophan pretreatment in healthy volunteers. World J Biol Psychiatry. 2004; 5(3):149-154. [PubMed: 15346539]

48. Spiga F, Lightman SL, Shekhar A, Lowry CA. Injections of urocortin 1 into the basolateral amygdala induce anxiety-like behavior and c-Fos expression in brainstem serotonergic neurons. Neuroscience. 2006; 138(4):1265-1276. [PubMed: 16488545]

49. Esler M, Lambert E, Alvarenga M, et al. Increased brain serotonin turnover in panic disorder patients in the absence of a panic attack: reduction by a selective serotonin reuptake inhibitor. Stress. 2007; 10(3):295-304. [PubMed: 17613943]

50. Johnson P, Lowry C, Truitt W, Shekhar A. Disruption of GABAergic tone in the dorsomedial hypothalamus attenuates responses in a subset of serotonergic neurons in the dorsal raphe nucleus following lactate-induced panic. J Psychopharmacol. 2008; 22(6):642-652. [PubMed: 18308791]

51. Garber, JC.; Barbee, RW.; Bielitzki, JT., et al. Guide for the Care and Use of Laboratory Animals (Institute for Laboratory Animal Research). Washington, DC: The National Academies Press; 2011.

52. Paxinos, G.; Watson, C. The Rat Brain in Stereotaxic Coordinates. San Diego, CA: Academic Press; 1998.

53. File SE. The use of social interaction as a method for detecting anxiolytic activity of chlordiazepoxide-like drugs. J Neurosci Meth. 1980; 2(3):219-238.

54. Gardner KL, Hale MW, Oldfield S, et al. Adverse experience during early life and adulthood interact to elevate $t p h 2$ mRNA expression in serotonergic neurons within the dorsal raphe nucleus. Neuroscience. 2009; 163(4):991-1001. [PubMed: 19647049]

55. Sajdyk TJ, Shekhar A. Excitatory amino acid receptors in the basolateral amygdala regulate anxiety responses in the social interaction test. Brain Res. 1997; 764(1-2):262-264. [PubMed: 9295221]

56. Shekhar A, Katner JS. Dorsomedial hypothalamic GABA regulates anxiety in the social interaction test. Pharmacol Biochem Behav. 1995; 50(2):253-258. [PubMed: 7740065]

57. Donner N, Handa RJ. Estrogen receptor beta regulates the expression of tryptophan-hydroxylase 2 mRNA within serotonergic neurons of the rat dorsal raphe nuclei. Neuroscience. 2009; 163(2): 705-718. [PubMed: 19559077]

58. Gardner KL, Hale MW, Lightman SL, et al. Adverse early life experience and social stress during adulthood interact to increase serotonin transporter mRNA expression. Brain Res. 2009; 1305:4763. [PubMed: 19781533]

59. Abrams JK, Johnson PL, Hollis JH, Lowry CA. Anatomic and functional topography of the dorsal raphe nucleus. Ann NY Acad Sci. 2004; 1018:46-57. [PubMed: 15240351]

60. Grubbs FE. Procedures for detecting outlying observations in samples. Technometrics. 1969; 11:121. 
61. Gardner KL, Thrivikraman KV, Lightman SL, et al. Early life experience alters behavior during social defeat: focus on serotonergic systems. Neuroscience. 2005; 136(1):181-191. [PubMed: 16182451]

62. Shanks N, Larocque S, Meaney MJ. Neonatal endotoxin exposure alters the development of the hypothalamic-pituitary-adrenal axis: early illness and later responsivity to stress. J Neurosci. 1995; 15(1 Pt 1):376-384. [PubMed: 7823142]

63. Shanks N, Lightman SL. The maternal-neonatal neuro-immune interface: are there long-term implications for inflammatory or stress-related disease? J Clin Invest. 2001; 108(11):1567-1573. [PubMed: 11733549]

64. Sidor MM, Amath A, MacQueen G, Foster JA. A developmental characterization of mesolimbocortical serotonergic gene expression changes following early immune challenge. Neuroscience. 2010; 171(3):734-746. [PubMed: 20816924]

65. Cowley DS, Dunner DL. Response to sodium lactate in panic disorder: relationship to presenting clinical variables. Psychiatry Res. 1988; 25(3):253-259. [PubMed: 3186860]

66. Gorman JM, Goetz RR, Dillon D, et al. Sodium D-lactate infusion of panic disorder patients. Neuropsychopharmacology. 1990; 3(3):181-189. [PubMed: 2114119]

67. Roche M, Commons KG, Peoples A, Valentino RJ. Circuitry underlying regulation of the serotonergic system by swim stress. J Neurosci. 2003; 23(3):970-977. [PubMed: 12574426]

68. Kelly KJ, Donner NC, Hale MW, Lowry CA. Swim stress activates serotonergic and nonserotonergic neurons in specific subdivisions of the rat dorsal raphe nucleus in a temperaturedependent manner. Neuroscience. 2011; 197:251-268. [PubMed: 21945646]

69. Johnson PL, Fitz SD, Hollis JH, et al. Induction of c-Fos in 'panic/defence'-related brain circuits following brief hypercarbic gas exposure. J Psychopharmacol. 2010; 25(1):26-36. [PubMed: 20080924]

70. Johnson PL, Hollis JH, Moratalla R, et al. Acute hypercarbic gas exposure reveals functionally distinct subpopulations of serotonergic neurons in rats. J Psychopharmacol. 2005; 19(4):327-341. [PubMed: 15982987]

71. Johnson PL, Lightman SL, Lowry CA. A functional subset of serotonergic neurons in the rat ventrolateral periaqueductal gray implicated in the inhibition of sympathoexcitation and panic. Ann NY Acad Sci. 2004; 1018:58-64. [PubMed: 15240352]

72. Johnson PL, Truitt WA, Fitz SD, et al. Neural pathways underlying lactate-induced panic. Neuropsychopharmacology. 2008; 33(9):2093-2107. [PubMed: 18059441]

73. Steinbusch, H. Serotonin-immunoreactive neurons and their projections in the CNS. In: Björklund, A.; Hökfelt, T., editors. Classical Transmitters and Transmitter Receptors inthe CNS. Amsterdam: Elsevier Science Publishers B.V; 1984. p. 68-125.

74. Kerman IA, Shabrang C, Taylor L, et al. Relationship of presympathetic-premotor neurons to the serotonergic transmitter system in the rat brainstem. J Comp Neurol. 2006; 499(6):882-896. [PubMed: 17072838]

75. Bandler R, Keay KA, Floyd N, Price J. Central circuits mediating patterned autonomic activity during active vs. passive emotional coping. Brain Res Bull. 2000; 53(1):95-104. [PubMed: 11033213]

76. Keay KA, Bandler R. Parallel circuits mediating distinct emotional coping reactions to different types of stress. Neurosci Biobehav Rev. 2001; 25(7-8):669-678. [PubMed: 11801292]

77. Graeff FG. Anxiety, panic and the hypothalamic-pituitary-adrenal axis. Revista Brasileira de Psiquiatria. 2007; 29:3-6. [PubMed: 17435917]

78. Underwood MD, Arango V, Bakalian MJ, et al. Dorsal raphe nucleus serotonergic neurons innervate the rostral ventrolateral medulla in rat. Brain Res. 1999; 824(1):45-55. [PubMed: 10095041]

79. Bago M, Dean C. Sympathoinhibition from ventrolateral periaqueductal gray mediated by 5HT(1A) receptors in the RVLM. Am J Physiol Regul Integr Comp Physiol. 2001; 280(4):R976R984. [PubMed: 11247817]

80. Bago M, Sprtel BM, Dean C. Modulation of sympathetic nerve activity by microinjection of the 5HT1A receptor agonist 8-OH-DPAT into the rostroventrolateral medulla. J Auton Nerv Syst. 1999; 76(2-3):127-134. [PubMed: 10412836] 
81. Ljubic-Thibal V, Morin A, Diksic M, Hamel E. Origin of the serotonergic innervation to the rat dorsolateral hypothalamus: retrograde transport of cholera toxin and upregulation of tryptophan hydroxylase mRNA expression following selective nerve terminals lesion. Synapse. 1999; 32(3): 177-186. [PubMed: 10340628]

82. Yoshida K, McCormack S, Espana RA, et al. Afferents to the orexin neurons of the rat brain. J Comp Neurol. 2006; 494(5):845-861. [PubMed: 16374809]

83. Johnson PL, Truitt W, Fitz SD, et al. A key role for orexin in panic anxiety. Nat Med. 2010; 16(1): 111-115. [PubMed: 20037593]

84. Kumar S, Szymusiak R, Bashir T, et al. Effects of serotonin on perifornical-lateral hypothalamic area neurons in rat. Eur J Neurosci. 2007; 25(1):201-212. [PubMed: 17241281]

85. Abrams JK, Johnson PL, Hay-Schmidt A, et al. Serotonergic systems associated with arousal and vigilance behaviors following administration of anxiogenic drugs. Neuroscience. 2005; 133(4): 983-997. [PubMed: 15916857]

86. Waterhouse BD, Mihailoff GA, Baack JC, Woodward DJ. Topographical distribution of dorsal and median raphe neurons projecting to motor, sensorimotor, and visual cortical areas in the rat. $\mathrm{J}$ Comp Neurol. 1986; 249(4):460-476. 478- 481. [PubMed: 3528236]

87. Ranade SP, Mainen ZF. Transient firing of dorsal raphe neurons encodes diverse and specific sensory, motor, and reward events. J Neurophysiol. 2009; 102(5):3026-3037. [PubMed: 19710375]

88. Pfleiderer B, Zinkirciran S, Michael N, et al. Altered auditory processing in patients with panic disorder: a pilot study. World J Biol Psychiatry. 2010; 11(8):945-955. [PubMed: 20586534]

89. Hale MW, Lowry CA. Functional topography of midbrain and pontine serotonergic systems: implications for synaptic regulation of serotonergic circuits. Psychopharmacology (Berl). 2011; 213(2- 3):243-264. [PubMed: 21088958]

90. Maron E, Toru I, Hirvonen J, et al. Gender differences in brain serotonin transporter availability in panic disorder. J Psychopharmacol. 2011; 25(7):952-959. [PubMed: 21148024]

91. Klein DF. Testing the suffocation false alarm theory of panic disorder. Anxiety. 1994; 1(1):1-7. [PubMed: 9160539]

92. Klein DF. False suffocation alarms, spontaneous panics, and related conditions. An integrative hypothesis. Arch Gen Psychiatry. 1993; 50(4):306-317. [PubMed: 8466392]

93. Davies SJ, Lowry CA, Nutt DJ. Panic and hypertension: brothers in arms through 5-HT? J Psychopharmacol. 2007; 21(6):563-566. [PubMed: 17901092]

94. Walker DL, Davis M. Double dissociation between the involvement of the bed nucleus of the stria terminalis and the central nucleus of the amygdala in startle increases produced by conditioned versus unconditioned fear. J Neurosci. 1997; 17(23):9375-9383. [PubMed: 9364083]

95. Walker DL, Toufexis DJ, Davis M. Role of the bed nucleus of the stria terminalis versus the amygdala in fear, stress, and anxiety. Eur J Pharmacol. 2003; 463(1-3):199-216. [PubMed: 12600711]

96. Hayano F, Nakamura M, Asami T, et al. Smaller amygdala is associated with anxiety in patients with panic disorder. Psychiatry Clin Neurosci. 2009; 63(3):266-276. [PubMed: 19566756]

97. Graeff FG. Serotonin, the periaqueductal gray and panic. Neurosci Biobehav Rev. 2004; 28(3): 239-259. [PubMed: 15225969]

98. Lowry, C.; Hale, M. Serotonin and the neurobiology of anxious states. In: Mueller, C.; Jacobs, B., editors. Handbook of Behavioral Neuroscience. Amsterdam: Elsevier; 2010. p. 379-397. 


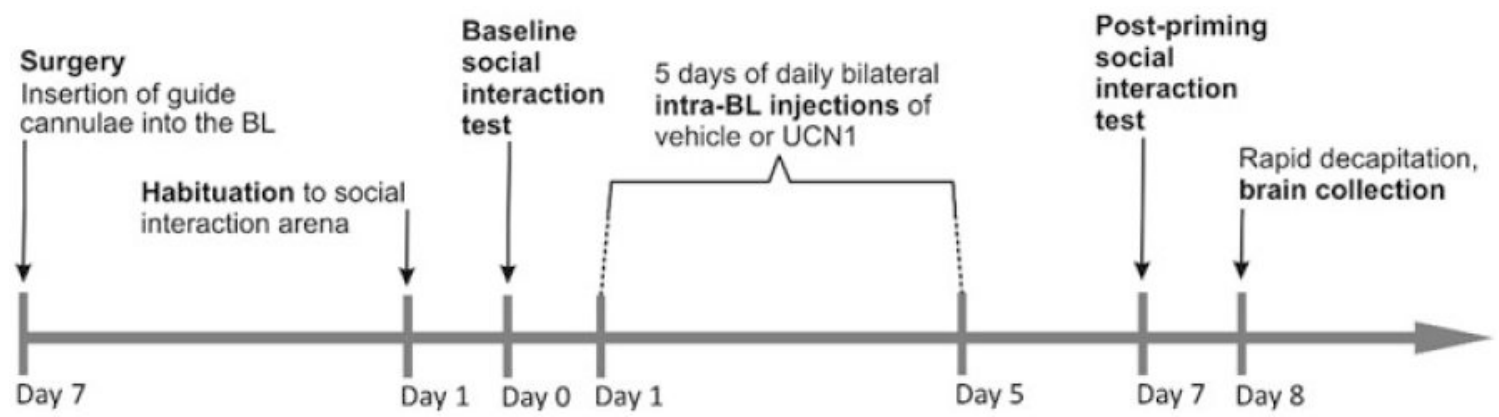

Figure 1.

Diagrammatic illustration of the experimental timeline. Adult, male rats underwent stereotaxic surgery to implant bilateral guide cannulae into the basolateral amygdaloid complex (BL) 6 days before being habituated to the social interaction (SI) arena, and 7 days before being tested for baseline anxiety-like behavior in the SI test. On Days 1-5, half of the rats received daily bilateral injections of vehicle (1\% bovine serum albumin (BSA) in sterile $0.9 \%$ saline, $n=8$ ) into the BL, whereas the other half was primed with a daily bilateral dose of urocortin 1 (UCN1, 6 fmoles/100 nl vehicle per side, $n=8$ ). On Day 7, 2 days after the last injection, both treatment groups were tested a second time in the SI paradigm. A third group of rats $(n=7)$ did not undergo stereotaxic surgery, behavioral testing, or any other treatment, and served as an undisturbed control group. On Day 8, all rats, including those from the undisturbed control group, were killed by rapid decapitation and their brains were collected for analysis of tph2 and slc6a4 expression using in situ hybridization histochemistry (ISHH). 

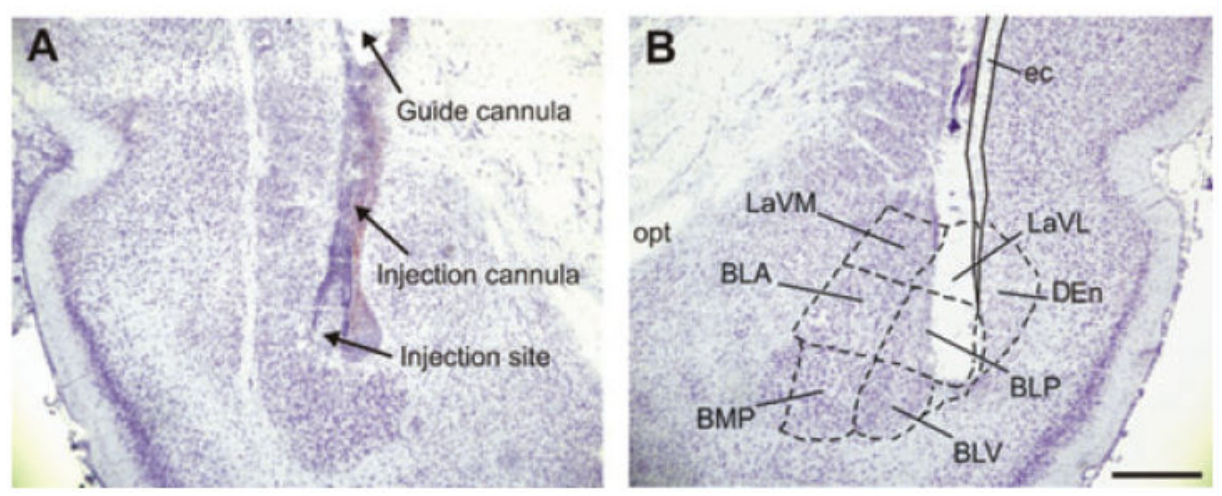

Figure 2.

Representative photomicrographs of cannula placements within the basolateral amygdaloid complex (BL). Shown is the placement of the injection cannula, and the injection site itself in both the left (A) and right (B) hemisphere of a cresyl violet stained coronal brain section at $-3.30 \mathrm{~mm}$ bregma from a urocortin 1 (UCN1)-primed rat. BLA, basolateral amygdaloid nucleus, anterior part; BLP, basolateral amygdaloid nucleus, posterior part; BLV, basolateral amygdaloid nucleus, ventral part; BMP, basomedial amygdaloid nucleus, posterior part; DEn, dorsal endopiriform nucleus; ec, external capsule; LaVL, lateral amygdaloid nucleus, ventrolateral part; LaVM, lateral amygdaloid nucleus, ventromedial part; opt, optic tract. Scale bar: $1 \mathrm{~mm}$. 

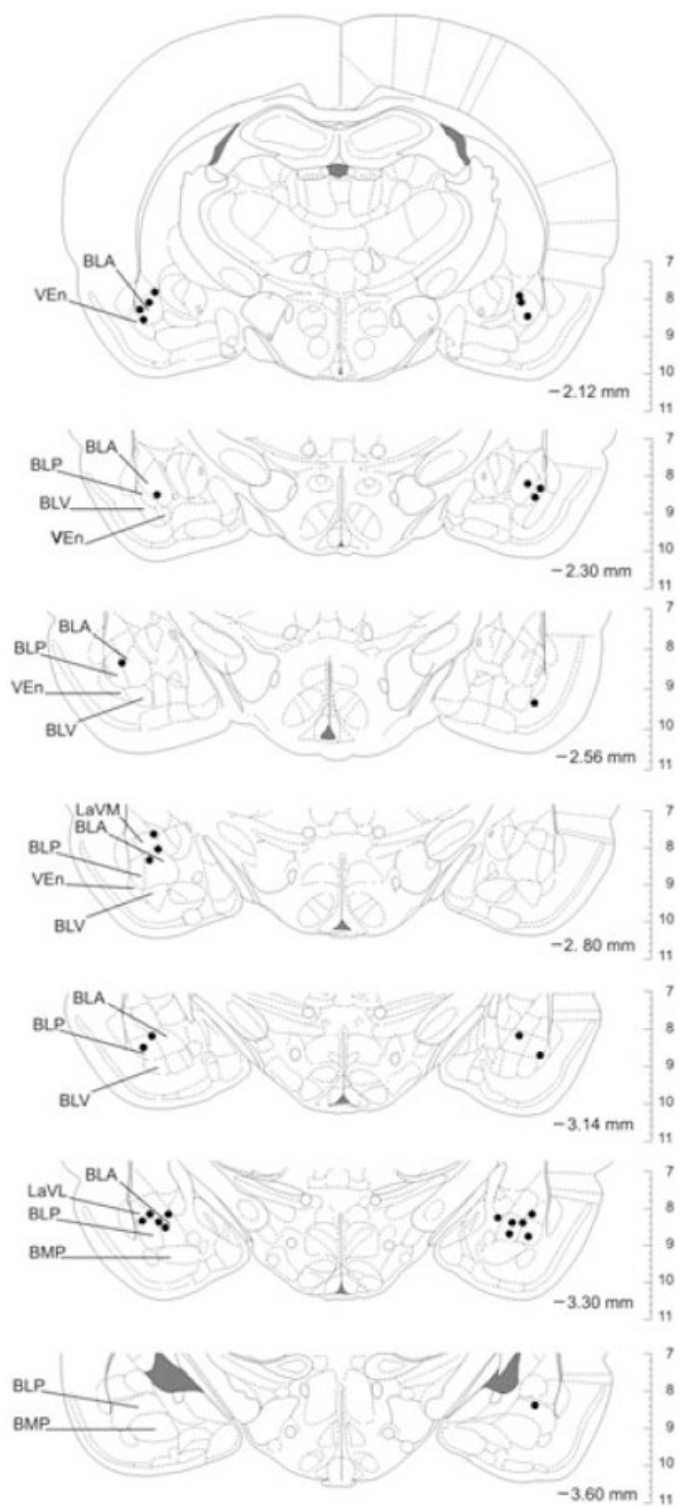

Figure 3.

Verification and mapping of cannula placements. Bilateral stereotaxic placements of guide and injection cannulae within the basolateral amygdaloid complex (BL) were verified via histochemistry and comparison with the rat brain atlas by Paxinos and Watson. ${ }^{[51]}$ Depicted are all injection sites (black dots) in rat brain sections from rostral ( $-2.12 \mathrm{~mm}$ bregma) to caudal ( $-3.60 \mathrm{~mm}$ bregma). The orientation of the brain sections matches the orientation of the viewer (left hemisphere on the left, right hemisphere on the right). All injection sites were considered successful because of their location within, or their proximity to, the BL region. The vertical scale on the right side of each brain section indicates the dorsoventral coordinates in millimeters. BLA, basolateral amygdaloid nucleus, anterior part; BLP, basolateral amygdaloid nucleus, posterior part; BLV, basolateral amygdaloid nucleus, ventral part; BMP, basomedial amygdaloid nucleus, posterior part; LaVL, lateral 
amygdaloid nucleus, ventrolateral part; LaVM, lateral amygdaloid nucleus, ventromedial part; VEn, ventral endopiriform nucleus. 


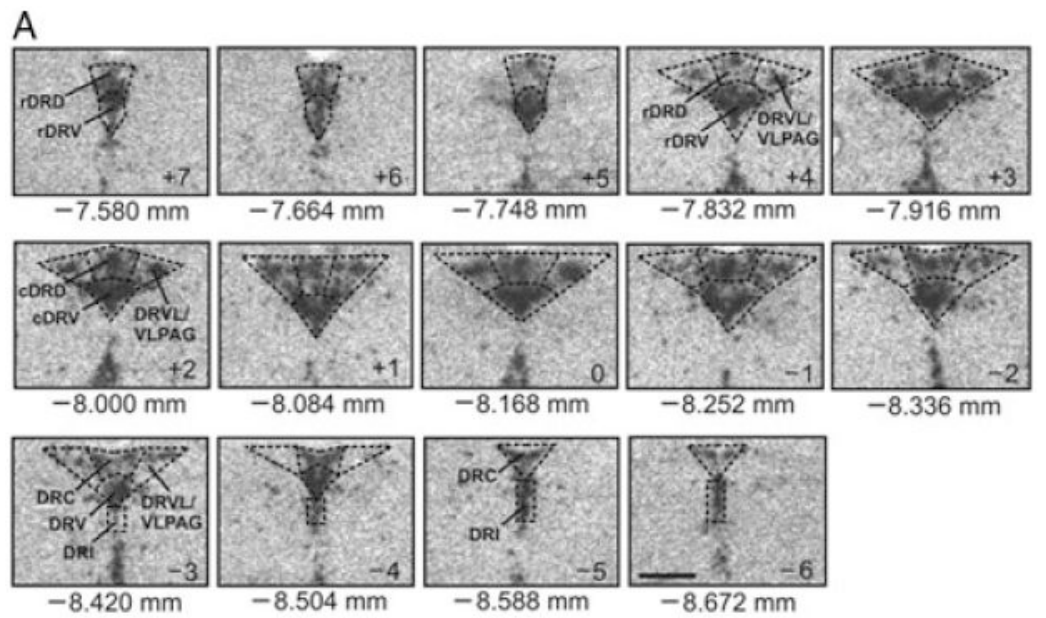

B
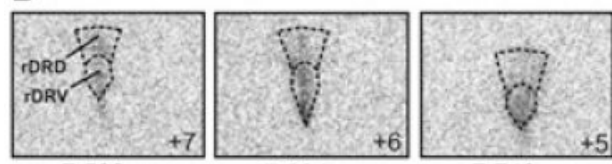

$-7.664 \mathrm{~mm}$

$-7.748 \mathrm{~mm}$
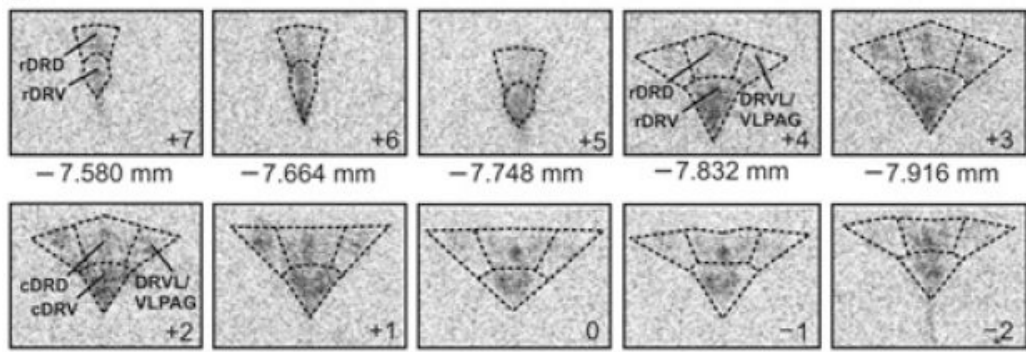

$-8.084 \mathrm{~mm}$

$-8.168 \mathrm{~mm}$
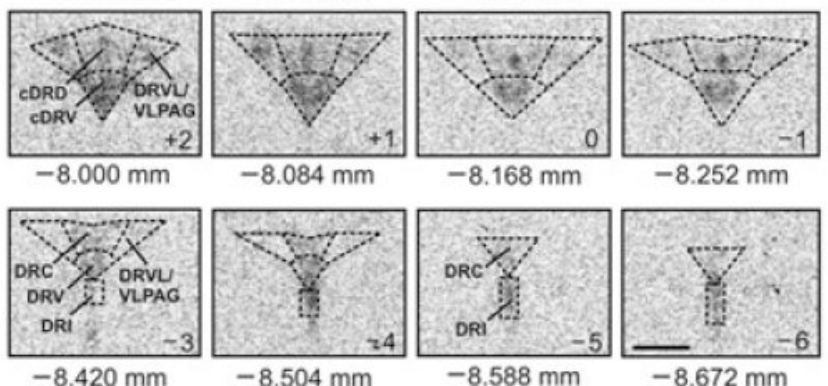

$-8.252 \mathrm{~mm}$
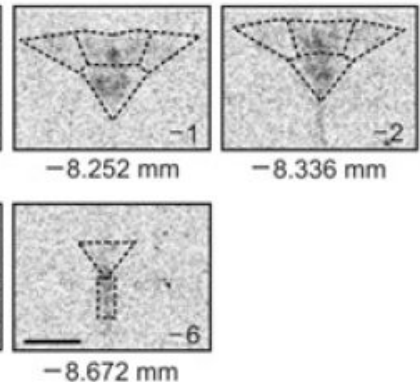

$-8.336 \mathrm{~mm}$

Figure 4.

Neuroanatomic atlases of rat tph2 and slc6a4 mRNA expression. Displayed (from top left to bottom right of each panel) are 14 representative coronal sections $(12 \mu \mathrm{m})$ that were used to measure tph2 (A) or slc6a4 (B) mRNA expression in all subdivisions of the midbrain dorsal raphe nucleus (DR) from rostral $(-7.580 \mathrm{~mm}$ bregma, designated level +7$)$ to caudal $(-8.672$ mm bregma, designated level -6). (A) Photomicrographs are autoradiographic images revealing the localization of hybridized 35-S-labeled cRNA probe complementary to tph2 mRNA. (B) Photomicrographs are autoradiographic images revealing the localization of hybridized 35-S-labeled oligonucleotide probe complementary to slc6a4 mRNA. Abbreviations are applicable to each following level until indicated differently. cDRD, caudal aspect of the dorsal raphe nucleus, dorsal part; cDRV, caudal aspect of the dorsal raphe nucleus, ventral part; DRC, dorsal raphe nucleus, caudal part; DRI, dorsal raphe nucleus, interfascicular part; DRVL, dorsal raphe nucleus, ventrolateral part; VLPAG, ventrolateral periaqueductal gray; rDRD, rostral aspect of the dorsal raphe nucleus, dorsal part; rDRV, rostral aspect of the dorsal raphe nucleus, ventral part. Scale bar: $1 \mathrm{~mm}$. 


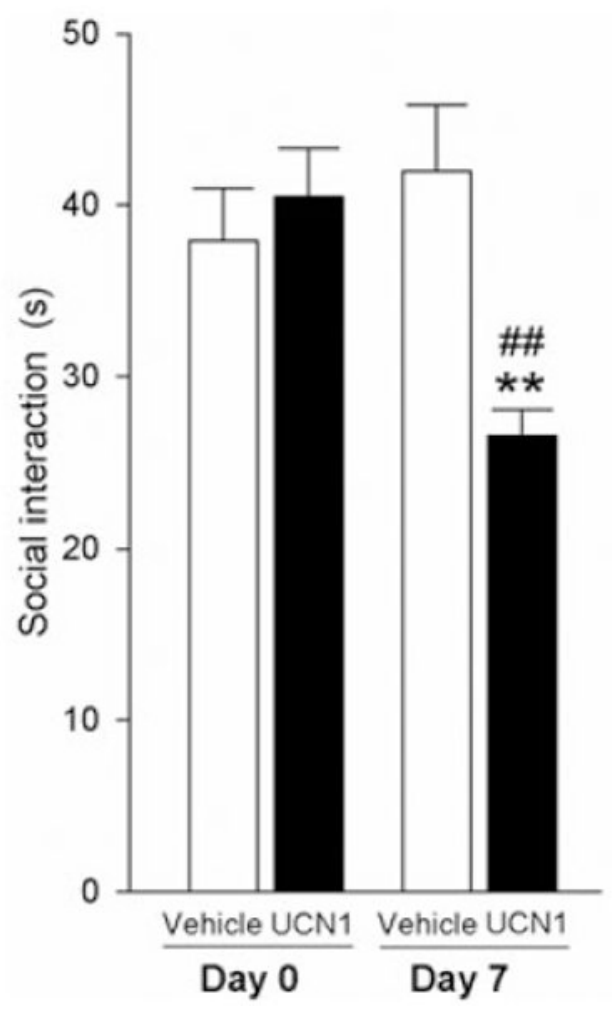

Figure 5.

Effects of amygdalar priming on anxiety-related behavior. SI behavior of adult, male rats before (Day 0) and after (Day 7) they received daily bilateral injections of vehicle (1\% bovine serum albumin (BSA) in sterile $0.9 \%$ saline, $n=8$ ) or urocortin 1 (UCN1, 6 fmoles/100 $\mathrm{nl}$ vehicle per side, $n=8$ ) into the basolateral amygdaloid complex (BL) for 5 consecutive days. One week prior to the behavioral testing, all rats had been implanted with bilateral guide cannulae targeting the BL. Shown is the mean (+ SEM) time (s, seconds) each treatment group spent interacting with a weight- and age-matched conspecific partner rat on Days 0 and 7 of the experiment. ${ }^{*} * P<.01$ versus postpriming vehicle. ${ }^{\# \#} P<.01$ versus Day 0. 

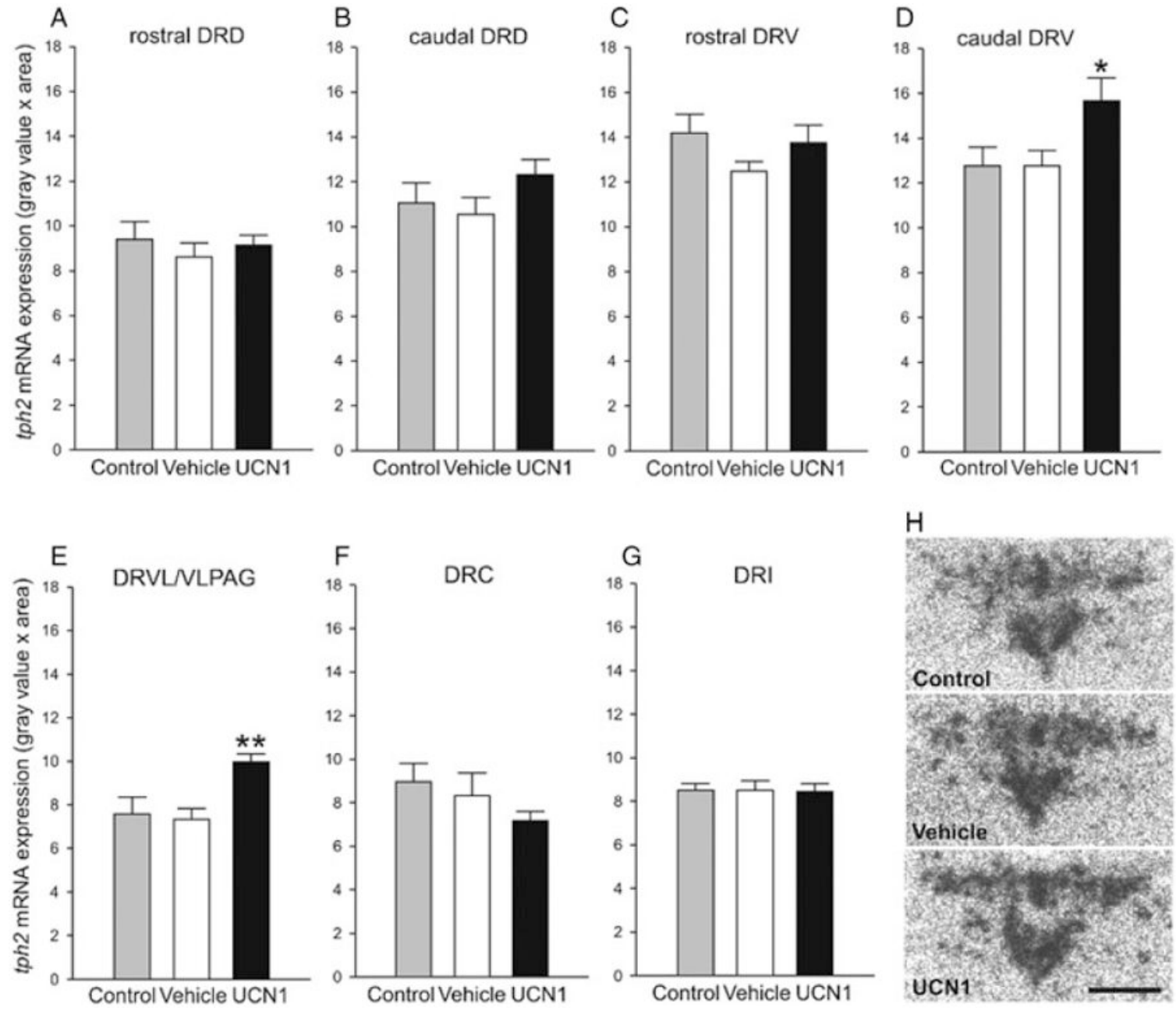

Figure 6.

Effect of amygdalar priming on tph2 mRNA expression. Effect of daily bilateral intrabasolateral amygdaloid complex $(\mathrm{BL})$ priming with either vehicle $(1 \%$ bovine serum albumin in sterile $0.9 \%$ saline, $n=8$ ) or urocortin 1 (UCN1, 6 fmoles/100 nl vehicle per side, $n=8$ ) for 5 consecutive days on the expression of tph 2 mRNA in the dorsal raphe nucleus (DR). All experimental rats were killed one day after the second SI test, meaning 3 days after the last intra-BL injection, and expression of tph 2 mRNA was compared to that of an undisturbed control group (control, $n=7$ ). Shown is the mean (+ SEM) tph 2 mRNA expression in each of the seven subdivisions of the DR $(\mathrm{A}-\mathrm{G}) .{ }^{*} P<0.05$ versus vehicle, $* * P<0.01$ versus vehicle; there were no differences between unhandled control rats and vehicle-primed rats. caudal DRD, caudal aspect of the dorsal raphe nucleus, dorsal part; caudal DRV, caudal aspect of the dorsal raphe nucleus, ventral part; DRC, dorsal raphe nucleus, caudal part; DRI, dorsal raphe nucleus, interfascicular part; DRVL/VLPAG, dorsal raphe nucleus, ventrolateral part/ventrolateral periaqueductal gray; rostal DRD, rostral aspect of the dorsal raphe nucleus, dorsal part; rostal DRV, rostral aspect of the dorsal raphe nucleus, ventral part. (H) Representative autoradiograms of tph2 mRNA expression at $-8.168 \mathrm{~mm}$ bregma (designated level 0) in undisturbed controls, and in vehicle- or UCN1treated rats. Scale bar: $1 \mathrm{~mm}$. 

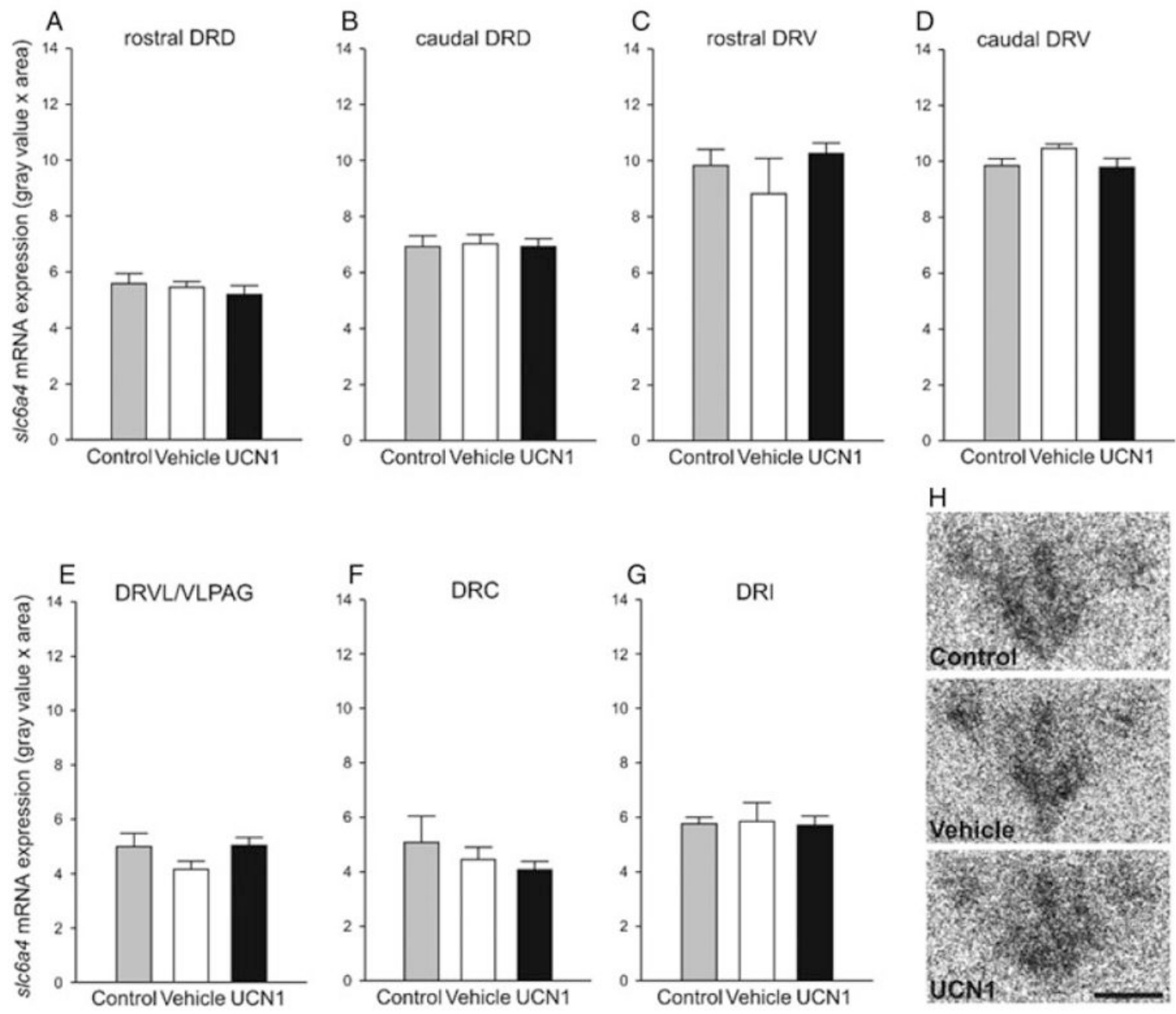

Figure 7.

Effect of amygdalar priming on slc6a4 mRNA expression. Effect of daily bilateral intrabasolateral amygdaloid complex (BL) priming with either vehicle (1\% bovine serum albumin in sterile $0.9 \%$ saline, $n=8$ ) or urocortin 1 (UCN1, 6 fmoles/100 nl vehicle per side, $n=8$ ) for 5 consecutive days on the expression of slc $6 a 4$ mRNA in the dorsal raphe nucleus (DR). All experimental rats were killed by rapid decapitation one day after the second SI test, meaning 3 days after the last intra-BL injection, and expression of slc6a4 mRNA was compared to that of an undisturbed control group (control, $n=7$ ). Shown is the mean (+ SEM) slc6a4 mRNA expression in each of the seven subdivisions of the DR (AG). caudal DRD, caudal aspect of the dorsal raphe nucleus, dorsal part; caudal DRV, caudal aspect of the dorsal raphe nucleus, ventral part; DRC, dorsal raphe nucleus, caudal part; DRI, dorsal raphe nucleus, interfascicular part; DRVL/VLPAG, dorsal raphe nucleus, ventrolateral part / ventrolateral periaqueductal gray; rostral DRD, rostral aspect of the dorsal raphe nucleus, dorsal part; rostral DRV, rostral aspect of the dorsal raphe nucleus, ventral part. $(\mathrm{H})$ Representative autoradiograms of slc6a4 mRNA expression at $-8.168 \mathrm{~mm}$ bregma (designated level 0) in undisturbed controls, and in vehicle- or UCN1-treated rats. Scale bar: $1 \mathrm{~mm}$. 


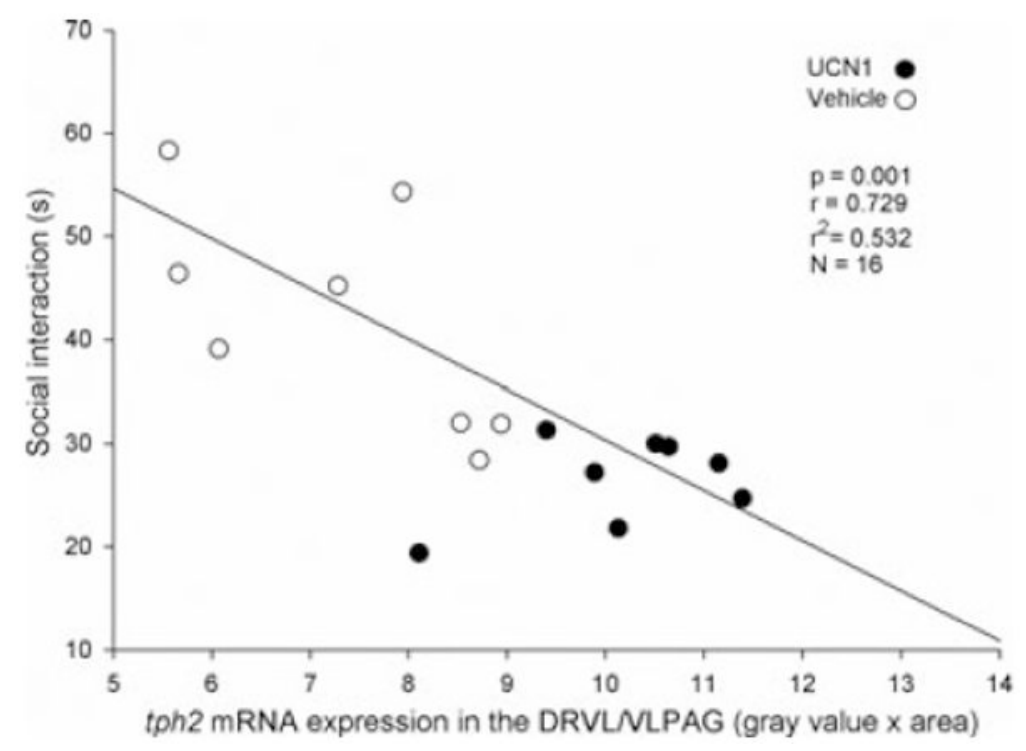

Figure 8.

Correlation of SI behavior and tph 2 mRNA expression. Displayed is the correlation of the time (s) that vehicle- or urocortin 1 (UCN1)-primed rats spent socially interacting with a weight- and age-matched conspecific partner rat in the SI test on Day 7 of the experiment and $t p h 2$ mRNA expression in the ventrolateral dorsal raphe nucleus/ventrolateral periaqueductal gray (DRVL/VLPAG), measured on Day 8. 


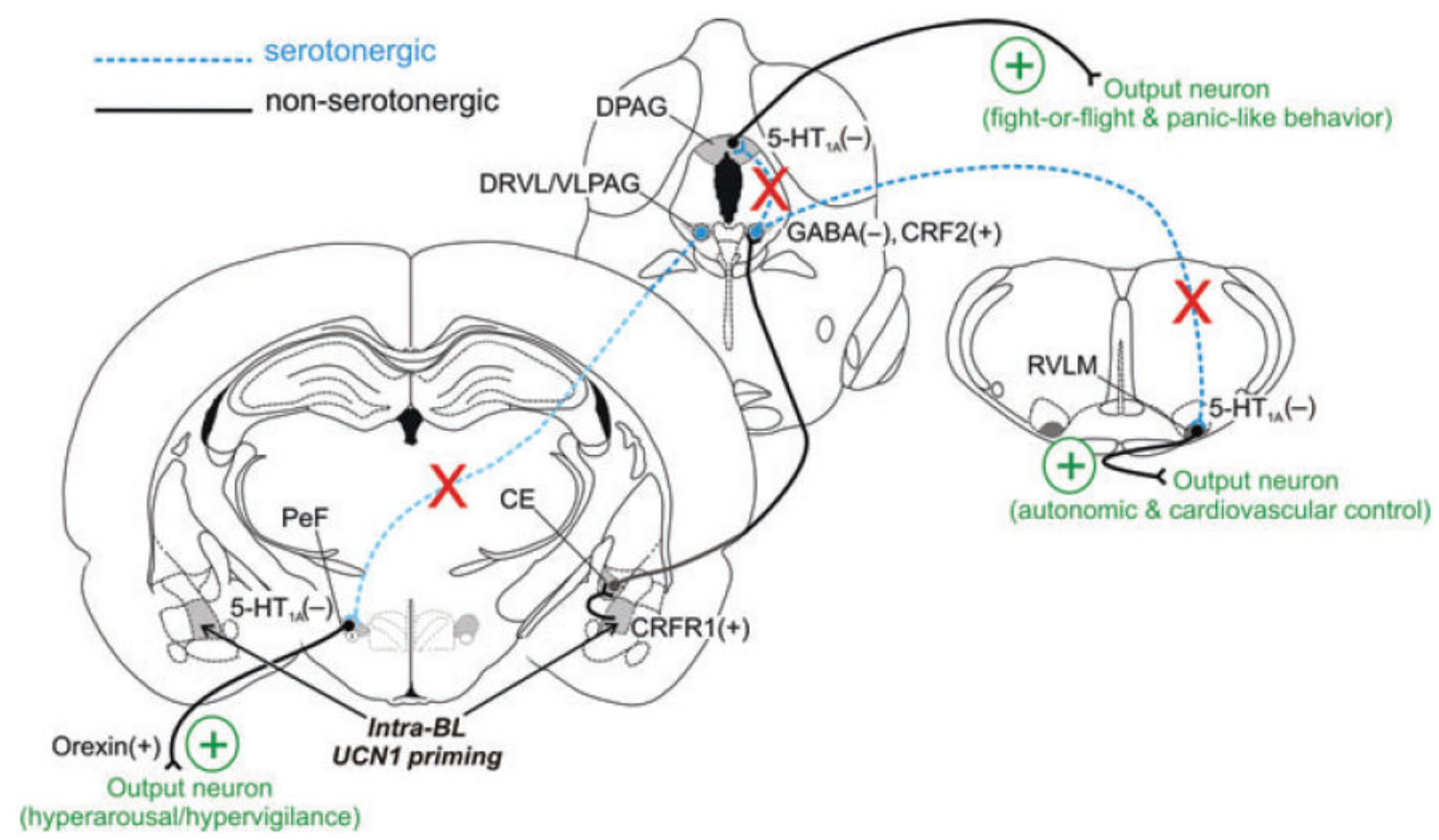

Figure 9.

Hypothetical model of mechanisms through which amygdalar priming leads to a chronic anxiety-like state. Urocortin 1 (UCN1) acts on corticotropin-releasing factor type $1\left(\mathrm{CRF}_{1}\right)$ receptors in the basolateral amygdaloid complex $(\mathrm{BL})$ to decrease the inhibitory $\gamma$ aminobutyric acid (GABA)-ergic tone, leading to a hyperexcitability of BL projection neurons. ${ }^{[25]}$ The BL gives rise to projections to both the central nucleus of the amygdala (CE) and the bed nucleus of the stria terminalis, lateral division, dorsal part (BSTLD), brain regions involved in fear- and anxiety-related behavior, respectively, ${ }^{[94,95]}$ that in turn project to the lateral wings (dorsal raphe nucleus, ventrolateral part, DRVL/ventrolateral periaqueductal gray, VLPAG) of the DR. ${ }^{[96]}$ The finding that amygdala priming enhances acquisition of fear-potentiated startle (dependent on the $\mathrm{CE}$ ) but not light-enhanced startle (dependent on the $\mathrm{BST}^{[89]}$ ) suggests that amygdala priming preferentially increases the excitability of the CE, leading to activation of the DRVL/VLPAG. Indeed, panic disorder patients show amygdala volume reductions in the corticomedial nuclear group that includes the CE. ${ }^{[96]}$ Activation of descending pathways from the CE increases tph 2 mRNA expression selectively in the DRVL/VLPAG region. Increased tph $2 \mathrm{mRNA}$ expression in DRVL/VLPAG serotonergic neurons increases tryptophan hydroxylase 2 (TPH2) protein and 5-HT release within the DRVL/VLPAG, which leads to activation of autoinhibitory 5$\mathrm{HT}_{1 \mathrm{~A}}$ receptors, resulting in an overall decreased serotonergic output from the DRVL/ VLPAG to distal target sites, such as the dorsal periaqueductal gray (DPAG), the rostral ventrolateral medulla (RVLM), and the perifornical hypothalamus (PeF). In the DPAG, decreased 5-HT action on postsynaptic 5- $\mathrm{HT}_{1 \mathrm{~A}}$ receptors leads to disinhibition of the $\mathrm{DPAG}^{[97]}$ and facilitation of panic/escape-like fight-or-flight responses. In the RVLM, decreased 5-HT action on postsynaptic 5- $\mathrm{HT}_{1 \mathrm{~A}}$ receptors promotes hypertension and sympathoexcitation. ${ }^{[98]}$ In the PeF, decreased 5-HT action on postsynaptic 5 - $\mathrm{HT}_{1 \mathrm{~A}}$ receptors leads to hyperactivity of orexin/hypocretin neurons, resulting in hypervigilance, hyperarousal, and panic-like responses. ${ }^{[83]}$ Failure to activate DRVL/VLPAG serotonergic 
neurons is associated with vulnerability to panicogenic agents such as sodium lactate. ${ }^{[50]}$ Decreased serotonergic output from the DRVL/VLPAG leads to a chronic anxiety-like state with increased vulnerability to panic-like responses. 